\title{
Current challenges in toxicological research: Evaluation of the developmental toxicity of manufactured nanomaterials
}

\section{Desafios atuais da pesquisa em toxicologia: Avaliação da toxicidade de nanomateriais manufaturados para o desenvolvimento}

\author{
Isabella Fernandes \\ Delgado \\ Instituto Nacional de \\ Controle de Qualidade em \\ Saúde, Fundação Oswaldo \\ Cruz (INCQS/Fiocruz), Rio \\ de Janeiro, RJ, Brasil \\ E-mail: isabella.delgado@ \\ incqs. fiocruz.br \\ Francisco J.R. \\ Paumgartten \\ Escola Nacional de Saúde \\ Pública Sergio Arouca, \\ Fundação Oswaldo Cruz \\ (ENSP/Fiocruz), Rio de \\ Janeiro, RJ, Brasil
}

\begin{abstract}
Nanomaterials are particles or fibers with at least one of the three dimensions in the size range between 1 and $100 \mathrm{~nm}$. Owing to unique physical and chemical properties, nano-sized particles (NPs) have a variety of industrial uses and are more and more prevalent in everyday life. However, despite the growing number of nanotechnology products, health risk assessment of NPs is in its early infancy. The potential adverse effects of NPs on prenatal development are even less well investigated. This article summarizes the literature on the developmental toxicity of NPs. Generally, the studies are very recent and include ex vivo experiments using non-mammalian species, in vitro assays (mouse embryonic stem cell test) and in vivo investigations using rodents. Very little has been published on the effects of NPs on the development and function of the human placenta or on the transference of NPs into the human embryo and fetus. Some limitations of using ex vivo and in vitro assays to predict adverse effects of NPs on human prenatal development are discussed in this overview. The structural and functional differences between the rodent and human placenta in early pregnancy and their possible relevance to the transplacental passage of NPs are also commented upon.
\end{abstract}

KEYWORDS: Nanoparticles; nanotoxicology; placenta; risk assessment; reproductive toxicity

\section{RESUMO}

Nanomateriais são partículas ou fibras que possuem pelo menos uma das três dimensões na faixa de tamanho entre 1 e $100 \mathrm{~nm}$. Em virtude das suas propriedades físico-químicas ímpares as nano partículas têm uma variedade de usos na indústria e cada vez mais fazem parte do nosso cotidiano. Entretanto, apesar do número crescente de produtos da nanotecnologia chegando ao mercado, a avaliação dos riscos das NPs para saúde está na sua infância. Os efeitos nocivos das NPs sobre o desenvolvimento pré-natal tem sido ainda menos investigados. Este artigo sumariza a literatura sobre os efeitos das NPs sobre o desenvolvimento. Os estudos são em geral muito recentes e incluem experimentos ex vivo empregando invertebrados e vertebrados não-mamíferos, ensaios in vitro (células tronco embrionárias de camundongos) e in vivo em roedores. Muito pouco tem sido publicado a respeito dos efeitos das NPs na placenta e sobre a passagem das NPs da mãe para o embrião e feto humanos. Algumas limitações dos ensaios ex vivo e in vitro para evidenciar potenciais perigos das NPs para o desenvolvimento prenatal humano são discutidas nesta revisão. As diferenças de estrutura e função entre a placenta de roedores e a placenta humana no período inicial da gravidez e a possível relevância delas para a transferencia transplacentária de NPs também são comentadas.

PALAVRAS CHAVE: Nanoparticulas; nanotoxicologia; placenta; avaliação de risco; toxicidade reprodutiva 


\section{Abbreviations}

NPs, Nano-sized particles; NNI, US National Nanotechnology Initiative; MCTI, Brazilian Ministry of Science, Technology and Innovation; AUC, area under the curve; $C_{\max }$, peak plasma, serum or blood concentration; PND, postnatal day; GD, gestational day; QSAR, Quantitative Structure Activity Relationships; EPR, Enhanced Permeability and Retention; EGFR, epidermal growth factor receptor; EST, mouse embryonic stem cell test; FETAX, Frog Embryo Teratogenesis Assay-Xenopus; MTT assay, MTT dye (3-[4,5-dimethylthiazol-2-yl]-2,5 diphenyl tetrazolium bromide) cytotoxicity assay ; SWCNT, single wall carbon nanotubes; MWCNT, multiwall carbon nanotubes; SCID, severe combined immunodeficiency mouse strain (lacking in T and B lymphocytes and immunoglobulins).

\section{Introduction}

Nano (n)-from the Greek "nannos” ("dwarf”)-refers to $10^{-9}$ of a particular unit (e.g., 1 meter $=10^{9}$ nanometers; 1 liter $=10^{9}$ nanoliters; 1 gram $=10^{9}$ nanograms). It is one of 20 Latin or Greek prefixes that denote decimal multiples $\left(10^{n}\right)$ or submultiples $\left(10^{-n}\right)$ of units in the International System of Units (SI). Over past decades, the prefix nano has also been used to define new fields of human endeavor such as the nanosciences (i.e., the study of the properties of ultra-small structures, materials and devices usually with dimensions ranging from 0.1 to $100 \mathrm{~nm}$ ) and nanotechnology (i.e., the design, characterization, production and application of structures, devices and systems by controlling shape and size on a nanometer scale).

The emergence of nanotechnology seems to have been inspired in a lecture (entitled "There's plenty of room at the bottom") delivered by Richard Phillips Feynman at the California Institute of Technology (Caltech, Pasadena CA) on December 29, 1959. Feynman, an outstanding American theoretical physicist and Nobel laureate, known for his contributions to quantum mechanics, outlined a world of novel technologies that would work and build machines on the smallest possible scale by, "maneuvering things atom by atom" at the ultimate frontier for miniaturization. He also noted that on such a reduced scale the magnitude of various physical phenomena might change, i.e., gravity would become less important while surface tension and Van der Waals attractions would become more important. The term nanotechnology, however, was first employed by Norio Taniguchi, a Japanese scientist, at a conference held in 1974. Talking about semiconductor processes, Taniguchi defined nanotechnology as consisting of, "the processing of, separation, consolidation and deformation of materials by one atom or one molecule". The idea of nanotechnology was further developed and popularized by Kim Eric Drexler in several articles and a book ("Vehicles of creation: the arrival of the nanotechnology era") published in 1986 1,2,3,4.

In 2000 , the US government created the National Nanotechnology Initiative (NNI) program, an interagency effort to support nanotechnology research and development it in ac- ademic, governmental and industrial laboratories across the country ${ }^{5}$. Along the same lines, in 2003, the Brazilian Ministry of Science, Technology and Innovation (MCTI) established a working group of experts to make recommendations for a government program to support the development of nanoscience and nanotechnology in Brazil. The US NNI defined nanotechnology as, "the understanding and control of matter of dimensions between approximately 1 and $100 \mathrm{~nm}$, where unique phenomena enable novel applications", while the Brazilian working group described it as, "a set of research, development and innovation actions that can arise from special properties of matter organized in structures, the dimensions of which are on the nanometric range scale" ${ }^{6,7}$.

Feynman, in his seminal lecture, pointed out that, when the dimensions of a material are extremely reduced, approaching the atomic or molecular level (nanometer scale), some of its physical properties may dramatically change. As dimensions of a material are reduced, physical properties initially remain unaltered, then small changes occur and when size drops below a certain level (e.g., <100 nm) drastic changes may occur. Some size-related changes, such as the increased surface area to volume ratio (or surface area per unit of mass), are gradual modifications that become more and more important as particle size decreases. Other changes in physical and chemical properties, however, occur at critical points when particle size reduction approaches the nanoscale. These "quantum effects" may involve changes in basic properties such as melting point and color, alterations in aerodynamic behavior and increases in the percentage of atoms and molecules in the material that are on the surface of the particle. All these changes of physical and chemical features may affect interactions of particles with biological systems and thus it seems fair to assume that the health effects and toxicity of materials can also be drastically affected by nanoscaling.

As far as safety regulation is concerned, nanotechnology products are usually defined by their size and not by chemical composition. There has been, however, some controversy over

$\mathrm{i}$ The definition recommended by the European Commission states that "Nanomaterial means a natural, incidental or manufactured material containing particles, in an unbound state or as an aggregate or as an agglomerate and where, for $50 \%$ or more of the particles in the number size distribution, one or more external dimensions is in the size range $1 \mathrm{~nm}-100 \mathrm{~nm}$ ". (2011/696/EU; Official Journal L, 275(2011) pp. 38-40). Although some consensus has been reached on the size range of nanomaterials (1-100 nm) (ISO 2012; http://www.iso.org/obp/ui/\#home), in fact there is no clear size threshold or point for changes in physicochemical properties, thus the chosen $100 \mathrm{~nm}$ cut off was an arbitrary and political choice rather than a science-based decision.

ii Occupational exposure to manufactured or engineered nanomaterials was originally regulated as "particulates not otherwise regulated" (PNOR) by US OSHA (2006) ${ }^{9}$. 
the definitions of the terms nanoparticle and nanoparticulate and how many dimensions must be less than $100 \mathrm{~nm}$ to meet such definitions ${ }^{8, \text { ii }}$. If at least one dimension (of a three-dimensional structure) is on the scale of 1 to $100 \mathrm{~nm}$, it is referred to as a "quantum well', while if two sides are on the nanometer scale, it is called a "quantum wire". If all three dimensions of the manufactured structure are of nanometer lengths it is referred to as a "quantum dot".

\section{Nanomedicine and nanotoxicology}

Nanomedicine is a novel term designating a promising field that has emerged from the successful marriage of nanotechnology and medicine ${ }^{10,11}$. The potential application and incorporation of nanotechnology into clinical practice mainly involves the development of new pharmaceutical products for treatment (e.g., nanoparticulate drug-delivery systems, nanoengineered prosthetics for implants), diagnosis, therapy and monitoring of morbid conditions (e.g., biomarkers, biosensors and contrasts for diagnostic imaging procedures) ${ }^{12,13,14}$.

One advantage of making use of nanotechnology in drug development is the possibility of overcoming the low aqueous solubility and poor bioavailability of some active ingredients ${ }^{15}$. The reduction of particle size leads to an increase in the dissolution rate of solid formulations (pills, tablets) and further nanosizing also enhances the rate and extent of active ingredient absorption (i.e., its oral bioavailability) to levels not attainable with typical micronized drug products ${ }^{16}$. In principle it is also possible to develop nanoparticulate systems that deliver active pharmaceutical ingredients at a target tissue or cell (e.g., tumors). iii Nanotechnology-based drug delivery systems are a particularly promising therapeutic approach in the area of oncology. Anticancer medicines are typically administered by intravenous infusion and many of their active ingredients are sparingly soluble. Among the major problems of oncologic drugs that can be successfully addressed by nanotechnology are: the penetration of cellular barriers that may otherwise inhibit arrival at the intended molecular target site; overcoming the multi-drug-resistance phenomenon, and improving the stability of the active ingredient in vivo. A study by Rios-Doria et al. ${ }^{17}$ has recently described a novel triblock copolymer to encapsulate daunorubicin (and other hydrophic anticancer drugs) ${ }^{\text {iv }}$ for intravenous injection that improves in vivo drug stability, $C_{\max }$ and AUC 17. Rios-Doria et al's study ${ }^{17}$ is a good example nanomedicine contributing to improving the effectiveness of currently available (hydrophobic) cancer chemotherapeutic agents. An innovation with even more impact is the creation of antican- cer drug formulations that can target tumor cells specifically thereby avoiding damage to non-malignant tissue and the associated adverse effects ${ }^{18,19}$. One of the differences between malignant and non-malignant tissues that seem to make this target-selective anticancer drug delivery feasible is the "enhanced permeability and retention" (EPR) ${ }^{v}$ phenomenon that occurs in solid tumors. Owing to deficient lymphatic drainage and poorly regulated angiogenesis, the unstructured and leaky vasculature of solid tumors allows nanoparticles to accumulate passively within the malignant tissue. Sengupta et al. ${ }^{19}$ used cisplatin as a template and developed nanoparticles (platinun (II) tethered to a cholesterol backbone) that exhibited significantly enhanced in vitro and in vivo ${ }^{\text {vi }}$ antitumor efficacy with decreased systemic and nephro-toxicity. The feasibility of this innovative approach has also been indicated in studies that showed that gold nanoparticles can be used to develop more selective and less toxic anticancer drugs ${ }^{23,24}$. It was shown, for instance, that TNF- $\alpha$ conjugated to gold nanoparticles selectively accumulates in tumor tissues and by doing so allows the delivery of high doses of this pro-inflammatory cytokine directly to the target site, circumventing the undesirable side-effects caused by elevated TNF- $\alpha$ levels in the systemic circulation ${ }^{24}$.

\section{Nanotoxicology or hazard assessment of nanoparticles}

The prefix "nano" was first added to toxicology early this century to define a new subcategory of this scientific discipline (i.e., nanotoxicology) some years after nanotechnology had taken center stage $25,26,27,28,29$. Nonetheless, the toxicity of natural and incidental ultrafine particles, including those on the nanoscale range, is not an entirely new topic for toxicologists, particularly for those who are concerned with the health effects of air pollution. It has long been known that the biological effects of inhaled aerosols and particles depend on their sizes and shapes so that only those smaller than $10 \mu \mathrm{m}$ eventually reach the lungs. Although contributing very little to the overall mass of particulate air pollution, ultrafine particles (i.e., those $<0.01 \mu \mathrm{m}$ in diameter) are found in high concentrations in polluted air and several authors believe that such nanometer scale particles play a causal role in the detrimental

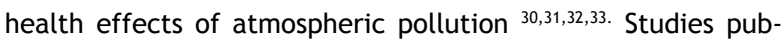
lished in the 1990s suggested that particles $<100 \mathrm{~nm}$ in diameter caused a greater than expected toxicity (inflammatory response) in the lungs when compared to similar particles of a larger size ${ }^{34,35 .}$

iii A drug delivered directly at a therapeutic target is reminiscent of Paul Ehrlich's concept of a "Magic Bullet" ("magische Kugel") or the ideal therapeutic agent that would selectively hit the pathogen causing no undesirable effects or injury to patient's organs and tissues.

iv In Rios-Doria et al's study ${ }^{17}$, particle sizes of encapsulated anticancer drugs were $30-80 \mathrm{~nm}$.

$\checkmark$ The general mechanism underlying the tumoritropic properties of some anticancer proteins was originally reported by Matsumara and Maeda' ${ }^{18}$ who also introduced the idea of EPR in 1986. Further studies described that the endothelial layer of tumor blood vessels is poorly structured and has larger intercellular gaps $(0.5-2.5 \mathrm{~mm} \text { wide })^{20,21,22}$.

vi Anti-tumor activity was tested in vivo in murine $4 \mathrm{~T} 1$ breast cancer and ovarian cancer models ${ }^{19}$

vii The " $\mathrm{t}^{4}$-transatlantic think tank for toxicology" workshop ${ }^{36}$, held in 2010 , at the $10^{\text {th }}$ anniversary of the US NNI, discussed strategies to assess the safety of nanotechnology products. The $t^{4}$ wokshop was organized by the Jonhs Hopkins Center for Alternatives to Animal Testing (CAAT), a center committed to the Three Rs (replacement, reduction and refinement of animal use). 


\section{Developmental toxicology of nanostructured materials}

In 2011, the report of an international workshop vii on the assessment of safety of nanotechnology products remarked that, "we are neither at the beginning of understanding the potential health effects, nor are we at the end, having all the answers the public, regulators, and policy makers require" ${ }^{36}$. According to workshop attendees' opinion, nanotoxicology was perhaps at "the end of the beginning" of creating a roadmap for a predictive testing strategy ${ }^{36}$. As far as reproductive and developmental hazards are concerned (i.e., developmental nanotoxicology), however, we are still taking the very first steps towards this goal.

In fact, a search in the Pubmed data base (01 September 2013) revealed that developmental nanotoxicology has not only emerged much later than the mother field of nanotechnology, but it has also elicited less research interest than the study of toxicity of nanomaterials to mature individuals (Table 1$)^{37}$.

Ema et al. ${ }^{38,}$ Campagnolo et al. ${ }^{39}$ and Sun et al. ${ }^{40}$ in 2010, 2012 and 2013, respectively, reviewed the literature on the reproductive and developmental toxicity of manufactured nanomaterials, while Juch et al. addressed the interference of NPs with early human placental function in $2013^{41}$. The foregoing reviews and the literature search in Pubmed (Table 1) consistently showed that there are relatively few studies on the reproductive and developmental toxicity of nanoparticles and that "next to nothing" is known about the effects of NPs on the placenta during early human pregnancy.

As shown in Table 2 the developmental toxicity of several engineered nanomaterials has been evaluated in non-mammalian animals including invertebrates (sea urchin, mollusks) and vertebrates (fish, frog) $42,43,44,45,46,47,48,49,50,51,52,53,54,55$. The embryonic development of zebrafish (Danio rerio) is the non-mammalian model most commonly used in studies of reproductive toxicity of NPs. Among the advantages of the zebrafish as a model are its fecundity, laying 200-300 eggs every 5-7 days, rapid embryo development and the fact that exposure of embryos occurs in vitro (e.g., in multiwell plates). Since zebrafish embryos remain transparent throughout the majority of development prior to hatching, the morphogenesis of the main organs and body structures (e.g., brain, notchord, heart, jaw, body segmentation) can also be observed in real time ${ }^{56}$. Mature fish eggs and developing embryos are surrounded by an acellular coat, the chorion. The extent to which the chorion is an effective protective barrier that prevents penetration of distinct chemicals has not been comprehensively assessed so that the chorion is generally removedviii to avoid "false negative" results in predictive embryotoxicity assays ${ }^{57,58}$. In principle nanoparticles ( $<100 \mu \mathrm{m}$ in one dimension) can penetrate the zebrafish embryo through the chorion pore canals (the sizes of which are 0.5-0.7 $\mu \mathrm{m}$ in diameter). In fact, it was demonstrated that Ag NPs enters the chorionic space by passive diffusion and Brownian movement ${ }^{42}$. However, several reports suggest that the chorion is an uptake barrier for SWCNP agglomerates ${ }^{54}$ and some NPs such as $\mathrm{TiO}_{2}{ }^{53}$ and fluorescent $\mathrm{SiO}_{2}$ and NPs that adhere to the surface of the chorion but do not enter the embryo ${ }^{51}$.

Developmental toxicities of a variety of manufactured NPs, including metal ( $\mathrm{Ag}, \mathrm{Au}, \mathrm{Co}, \mathrm{Cu}, \mathrm{Ti}, \mathrm{Zn}$ ), silica and carbon

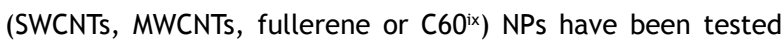
in fish (zebrafish ${ }^{42,43,45,49,50,53,54,55}$ and Japanese Medaka fish ${ }^{46}$ ), frog (FETAX assay ${ }^{52}$ ), mollusks (oyster ${ }^{50}$ and freshwater snails ${ }^{48}$ ), and sea urchin ${ }^{44,47}$ embryos. As shown in Table 2, exposure of non-mammalian embryos to a diversity of NPs gives rise to hatching delays, abnormal morphogenesis, increased embryo mortality and other adverse developmental outcomes. In some cases (e.g., fullerene $\mathrm{C60}$ ), evidence has been presented that the oxidative stress elicited by the NP is the underlying mech-

Table 1. Number of articles dealing with nanotechnology, nanotoxicology and reproductive and developmental toxicity of nanoparticles found in the Pubmed data base in 2013 using different combinations of search terms.

\begin{tabular}{lcccc}
\hline Search terms & Articles (No) & First published (year) & Articles in 2012 (No) & Articles in 2013* (No) \\
\hline Nanotechnology & 41,908 & $1991+$ & 5,920 & 3,025 \\
Nanoparticle + toxicity & 6,791 & $1982++$ & 1,528 & 1,013 \\
Nanotoxicology & 635 & 2004 & 237 & 191 \\
Nanoparticle + pregnancy & 129 & 1992 & 11 & 18 \\
Nanoparticle + placenta & 67 & 1999 & 17 & 13 \\
Nanoparticle + developmental toxicity & 91 & 2006 & 23 & 26 \\
Nanotoxicology + pregnancy & 9 & 2009 & 4 & 4 \\
Nanotoxicology + placenta & 5 & 2011 & 1 & 3 \\
\hline
\end{tabular}

* As of September 1st, 2013. + A remarkable paper by Kim Drexler (Nanotechnology: the past and the future) was published in 1992. ++ A 1982 study by Kante et $a^{37}$ with polyalkylcyanoacrylate NPs was the oldest found in Pubmed data base.

viii Under laboratory test conditions, zebrafish embryos develop normally outside their chorions. The dechorination can be achieved mechanically by using forceps and an enzymatic pretreatment (pronase) that makes the chorion easier to remove.

ix Fullerenes are composed entirely of carbon (e.g., 60 carbons) and may have different forms and shapes such as a hollow sphere, ellipsoid or tube. Carbon nanotubes are cylindrical fullerenes that are usually only a few nanometers wide and range from a micrometer to several millimeters in length. 


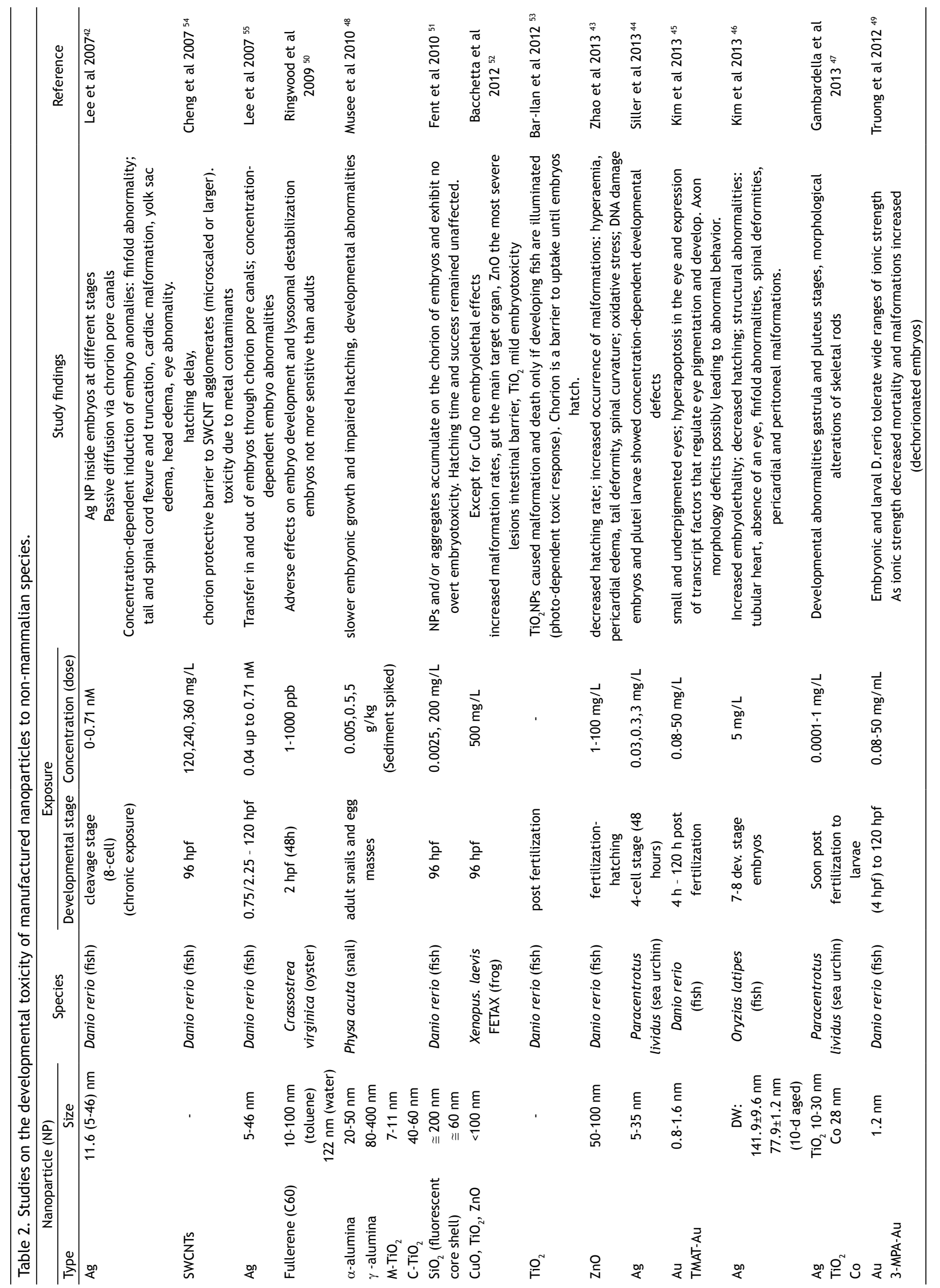


anism through which detrimental effects on the embryo are produced ${ }^{59}$. NP stability in the assay medium, local release of ions and the tendency of some NPs to agglomerate ${ }^{x}$ with age (under certain experimental conditions) should be taken into account when a test result is interpreted. It should be borne in mind that toxicokinetics and embryotoxicity of fresh (predominantly singlet) and aged (predominantly agglomerated) NPs may differ markedly.

A key issue in creating a roadmap for a NP developmental toxicity testing strategy is how to balance cost-effectiveness and feasibility in order to evaluate an ever-growing number of nanotechnology products entering the market in a timely manner, with assays' or tiered test schemes' value in predicting potential hazards to human embryos.

The zebrafish embryo assay has the advantage of being sensitive, easy and rapid to conduct and relatively inexpensive. As even the time-consuming mature egg dechorination step allows automation, an optimized zebrafish embryo assay seems to be, as yet, the most suitable ex vivo test for the high throughput screening of developmental hazards of NPs ${ }^{58}$.

Some authors proposed the mouse embryonic stem cell test (EST) as a valuable in vitro tool for screening NPs for developmental toxicity ${ }^{60}$. Conducting both in vivo (mouse) and in vitro tests (EST) on the embryotoxicity of carbon nanotubes (SWCNTs), Pietroiusti et al. ${ }^{61}$ concluded that the in vitro EST predicted in vivo results and identified oxidized SWCNTs as being more toxic than their non-oxidized (pristine) counterparts. Park et al. ${ }^{62}$ also reported that the EST detected a concentration-dependent inhibition of the differentiation of stem cells into contracting cardiomyocites by silica NPs of 10 and $30 \mathrm{~nm}$ (primary sizes), while silica NPs of 80 and $400 \mathrm{~nm}$ (primary sizes) had no effect up to the highest concentration tested.

However, the predictive value of developmental toxicity tests conducted on non-mammalian species, or in mammalian embryonic stem cells in vitro (EST) is limited. The placenta is a potential target organ for NP toxicity and the interference of nanomaterials with placental development and function may eventually result in preterm delivery, prenatal growth retardation, congenital malformations and/or gestational losses $63,64,65,66,67,68$.

If not secondary to placental dysfunction and/or disturbances in maternal homeostasis (i.e., maternal toxicity), adverse effects of NPs on prenatal development arise from the transference of NPs via the placenta into the embryonic/fetal compartment (Figure 1).

In non-mammalian test systems, eggs (and the embryos within the eggs) are directly exposed and thus these assays cannot anticipate the indirect (maternally and or placentally mediated) effects of NPs. Moreover, to enhance test sensitivity, possible barriers to penetration of test substances into the egg are removed, as are the chorion in the zebrafish assay and the jelly coat in the FETAX (frog) test ${ }^{69} .{ }^{\mathrm{xi}}$ Zebrafish and other non-mammalian test systems, therefore, can detect potential

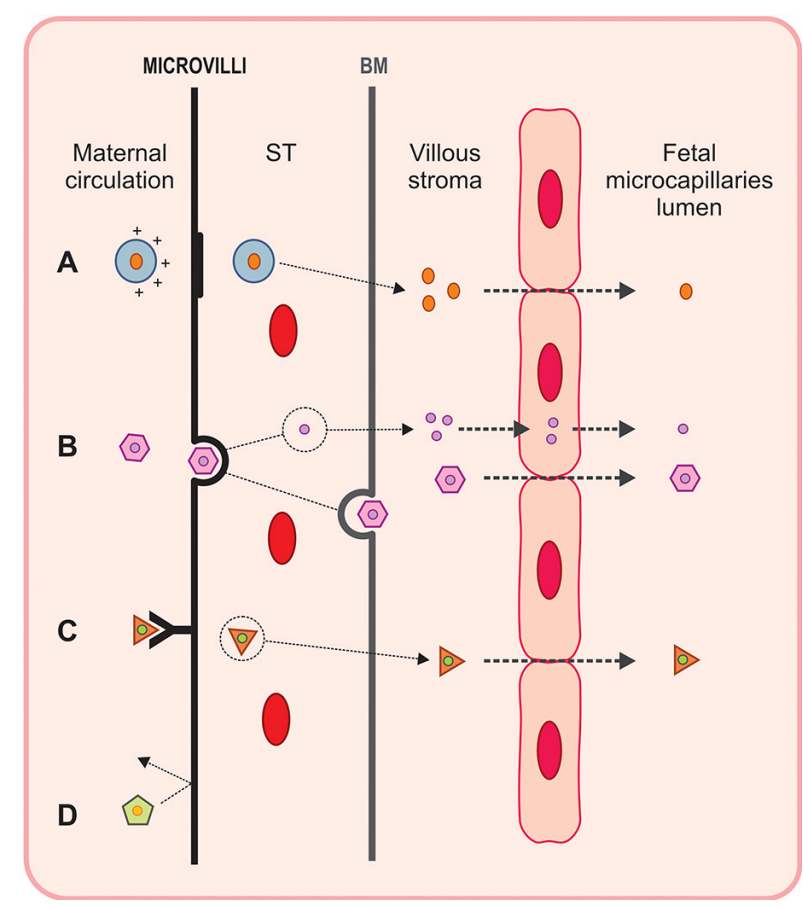

Figure 1. Mechanisms by which nanoparticles (NPs) and NP-delivered drugs found in the maternal blood can penetrate the human placenta and reach the developing embryo or fetus. The interface between maternal circulation and embryonic or fetal blood involves the syncytiotrophoblast (ST, a multi-nucleated terminally differentiated syncytium formed by fusion of cytotrophoblast cells), the matrix or supporting connective tissue of the chorionic villi in which blood vessels are found (VS, villous stroma) and the endothelial lining (a single layer of flattened cells) of fetal capillaries. A- Fusion with ST membrane. Cationic NPs and liposomes in the maternal blood may fuse with ST membrane and enter the cytoplasm where they can be disassembled thereby releasing their contents directly into ST cytosol. NP contents then diffuse to the villous stroma and the fetal capillary entering its lumen. An additional possibility (not depicted in the Figure) is the NP or liposome to remain intact within the cytoplasm and be fused with the ST basal membrane (BM) thereby releasing its contents into the villous stroma. B - Endocytosis. NP might be taken by endocytosis and either be degraded (in endosomes) thereby releasing their contents in the ST cytosol, or be transported via transcytosis to the villous stroma. Moving by simple diffusion the NPs (via pores between endothelial cells), or their contents (via both pores and endothelial cell cytoplasm) may then reach the lumen of the fetal capillary. C- Receptormediated mechanism. Ligand-modified NPs might bind to ST apical membrane receptor undertaking endocytosis. They may either be disassembled releasing their contents into the ST cytosol or be transferred by transcytosis into villous stroma. D-NP with certain features in terms of dimensions, charge, or surface composition may fail to penetrate the apical membrane of the ST thereby being unable to cross from the maternal to the fetal compartment. In any of cases of NPs that penetrate the apical membrane of ST $(A, B, C)$ an additional possibility is the retention of the intact NPs within the ST cytoplasm.

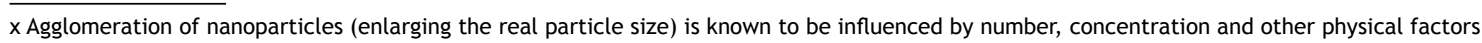


developmental toxicants that would not reach the mammalian embryo owing to the protective roles of the placenta and the maternal organism but, cannot detect harmful effects on the embryo arising from maternal toxicity and placental dysfunction. In other words, test systems (in non-mammals or in vitro) in which embryo exposure to NPs do not occur through the placenta are prone to yielding both false positive and false negative results with respect to potential hazards to developing mammalian/human conceptuses.

\section{Transplacental transfer and toxicity to mammalian embryos}

Kinetic studies of classical xenobiotic compounds suggest that highly hydrophilic and large molecules $(>1 \mathrm{kDa})$ are unlikely to be transferred across the placenta to the conceptus ${ }^{\mathrm{xi}}$. Nonetheless, as highlighted by Maynard et al. ${ }^{29}$, due to abrupt size-dependent changes in interactions with biological systems, the toxicity of engineered NPs (an "emergent risk") may arise from the unanticipated penetration of particles and fibers into tissues normally inaccessible to large molecules and particles ${ }^{29}$.

As shown by studies depicted in Table 3, maternal exposure to a variety of manufactured NPs was associated with harmful effects on mouse and rat embryos ${ }^{61,70,72,73,74,75,76,77,78,79,80}$ $, 81,82,83,84$. In at least three studies $73,77,82, x i i$, NPs were detected in the prenatally exposed offspring thereby indicating that tested NPs were transferred to the developing conceptus across the placenta. Blum et al. ${ }^{81}$, however, detected NPs (CdO) in the placenta and maternal organs of treated mice but not in their fetuses. Therefore, the embryotoxic effects of CdO NPs noted by the authors (e.g., delayed fetal and neonatal growth) were probably secondary to effects on the placenta and/or maternal toxicity (Table 3).

Overall, the rodent studies performed to date indicate that the exposure of pregnant females to different types of NPs may result in a variety of adverse outcomes of pregnancy such as embryo mortality, intra-uterine growth retardation, structural anomalies, and altered gene expression in the prenatally exposed offspring (Table 3). Some studies have provided additional kinetic data suggesting that developmentally toxic NPs crossed the placenta so that embryos were directly exposed. In at least one case, however, embryotoxic effects of NPs seemed to have been secondary to maternal and/or placental toxicity ${ }^{81}$. The absence of discernible adverse effects on embryo development even when NP exposure resulted in marked maternal toxicity has also been reported ${ }^{79}$. In a study by Chan \& Shiao ${ }^{83}$ mouse blastocysts were exposed to
NPs (CdSe QDs) in vitro, and then implanted into dams' uteri. In this case, the authors found detrimental effects of tested NPs on embryo development both in vitro (e.g., blastocyst cell apoptosis) and in vivo after transfer and implantation of in vitro-exposed embryos.

Owing to interspecies differences with respect to placental structure and function, toxic effects of NPs on development noted in rodents may not occur in humans 85 (Tables 4,5, Figure 2). In the rat, the inverted visceral yolk sac (intimately apposed to the uterine tissues) is the major structure mediating maternal and embryonic exchanges in early pregnancy (GD 7.5-12) ${ }^{85,86}$. In humans, however, there has been no indication that histiotrophic nutrition (via a yolk $\mathrm{sac}$ ) is an important pathway for nutrient acquisition vis a vis chorionic villi mediated hemotrophic exchanges ${ }^{86}$. It has been demonstrated that substances that inhibit rodent yolk sac function such as trypan blue and concanavalin A are also teratogenic ${ }^{87,88}$. The previously mentioned interspecies differences in placental structure and function, suggest that inhibitors of yolk sac mediated maternal-embryonic exchanges in rodents are unlikely to cause similar teratogenic effects in humans. Although an explanation for some of the embryotoxic effects in Table 3, whether or not NPs affect rodent yolk sac mediated maternal-embryonic exchanges and the extent to which they do so remain largely unclear.

Currently little is known about the transplacental transport of engineered NPs and whether NPs interfere with placental function in humans ${ }^{64,65}$. Only a few studies have addressed these crucial questions. Myllynen et al. ${ }^{67}$ observed that PEGylated ${ }^{\mathrm{xiv}}$ gold NPs (10-30nm in diameter) did not cross (over a $6 \mathrm{~h}$ perfusion test) the ex vivo perfused human placenta in detectable (ICP-MS) amounts. The authors also noted that gold NPs were taken up by the syncytiotrophoblast cell layer (possibly via non-specific endocytosis), a finding suggesting that the placenta may act as a sequestration organ for these NPs. Wick et al. ${ }^{68}$ also used an ex vivo placental perfusion method (applied in the maternal to fetal direction for $6 \mathrm{~h}$ ) to investigate transplacental transport of fluorescently labeled polysterene beads (sizes 50-500 nm). According to the study's results, polystyrene NPs smaller than $240 \mathrm{~nm}$ exhibited a size-dependent ability to cross the placenta in the direction of the fetal circulation and that transfer process was apparently saturable and possibly involved an endocytotic mechanism. A recent study by Sønnegaard-Poulsen et al. ${ }^{66}$ using an in vitro (BeWo b30 choriocarcinoma cell line, MTT cytotoxicity assay) and an ex vivo (perfused human placenta) model found that silica NPs decreased BeWo cell viability at concentrations higher than $100 \mu \mathrm{g} / \mathrm{mL}$. The authors also noted that the percentage of sili-

$\mathrm{xi}$ In the FETAX assay ${ }^{69}$ after frog egg laying, the jelly coat (a thick, sticky coating surrounding the egg) is removed by gently swirling the egg mass with a solution of L-cysteine. This de-jellying of embryos is undertaken to facilitate xenobiotic penetration of the egg thereby enhancing assay sensitivity to developmental toxicants.

xii Exceptions to this rule are large macromolecules specifically transported by the synctiotrophoblast, for example lgG (from the $13^{\text {th }}$ week of human pregnancy onwards).

xiii In Jo et al's study, pups underwent euthanasia on PND4 and so transference of NPs to pups via the maternal milk cannot be ruled out in this case. xiv PEGylation is a covalent attachment of polyethylene glycol (PEG) polymer chains to NP or another molecule. The covalent attachment of PEG to a drug or therapeutic protein can "mask" the NP or macromolecule from the host's immune system, increase its water solubility and hydrodynamic size (size in solution), and reduce its renal clearance, thereby prolonging its circulatory time. 


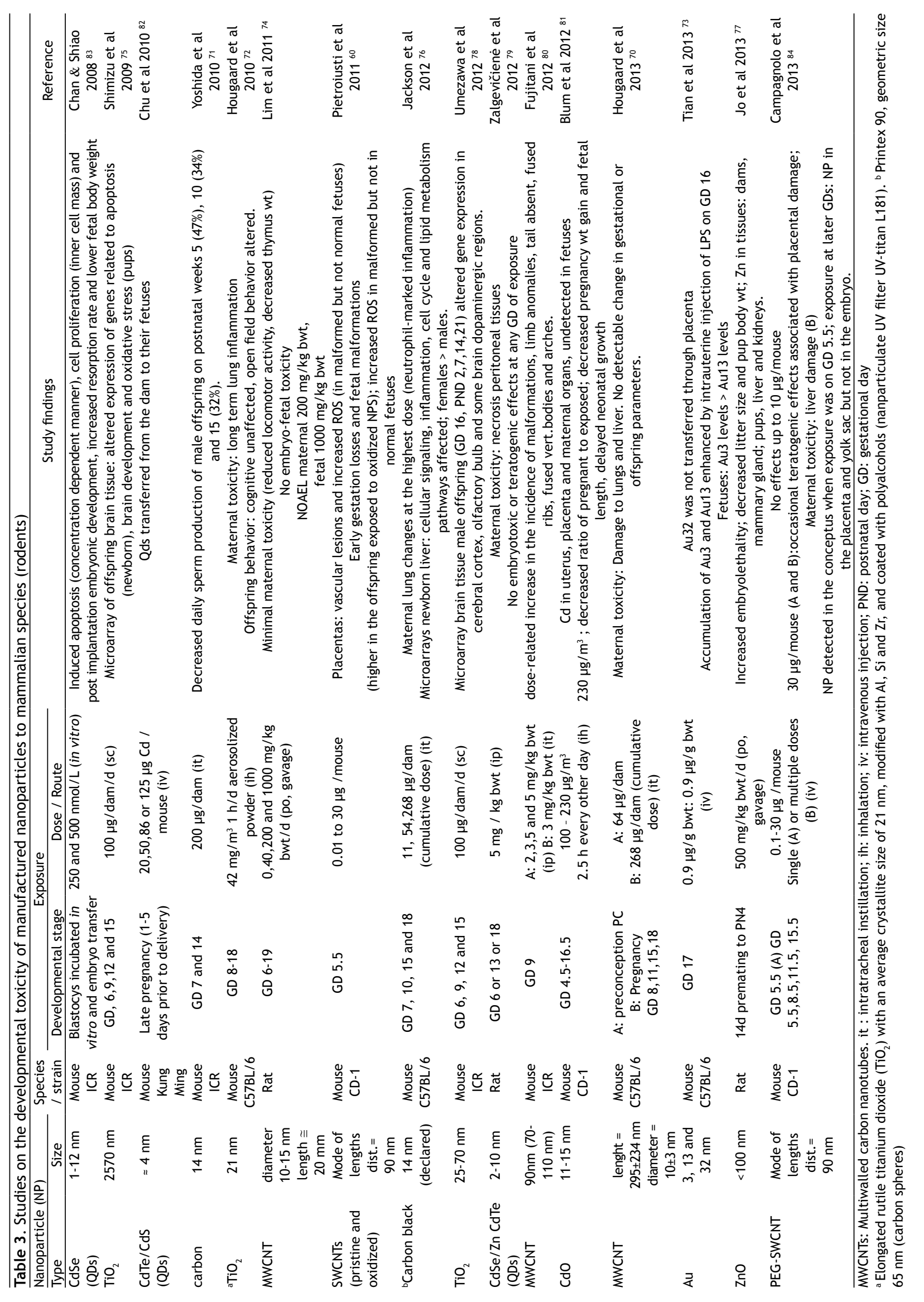




\begin{tabular}{|c|c|c|c|c|}
\hline \multirow{2}{*}{ Feature } & \multicolumn{2}{|c|}{ Rodents } & \multicolumn{2}{|c|}{ Primates } \\
\hline & rat & mouse & Rhesus monkey & human \\
\hline Gestation length (d) & 22 & 19 & 166 & 266 \\
\hline Implantation (GD) & $5-6$ & 5 & 9 & $6-7$ \\
\hline \multicolumn{5}{|l|}{ Implantation } \\
\hline early & eccentric & eccentric & superficial & interstitial \\
\hline late & interstitial & interstitial & & \\
\hline Shape & discoid & discoid & bidiscoid & discoid \\
\hline \multicolumn{5}{|c|}{ Placenta (fetal membranes) } \\
\hline early & inverted yolk sac & inverted yolk sac & chorioallantoic & chorioallantoic \\
\hline definitive & chorioallantoic & chorioallantoic & chorioallantoic & chorioallantoic \\
\hline
\end{tabular}

Implantation types: 1) superficial: chorionic sac is in contact with uterus lumen; 2) eccentric: chorionic sac is in a "pocket" partially separated from uterus lumen; 3) interstitial: chorionic sac is within the uterine wall losing contact with uterus lumen. Chorioallantoic placenta: formed by the chorion (outermost avascular membrane of embryonic vesicle) that is augmented by and receives vascularization from the allantois. Inverted yolk sac placenta: formed by membranes of rodent large yolk sacs, it is at times called "inverted" because outer yolk sac membranes become discontinuous at the apposition to the uterine wall, leaving the inner yolk sac membrane nearly in contact with the uterine lumen and epithelium. Rodents do not develop the definitive chorioallantoic placenta until a circulatory system is operative (i.e., in rats GD 11-11.5) whereas yolk sac placentas are not formed in primates.

A) ECCENTRIC

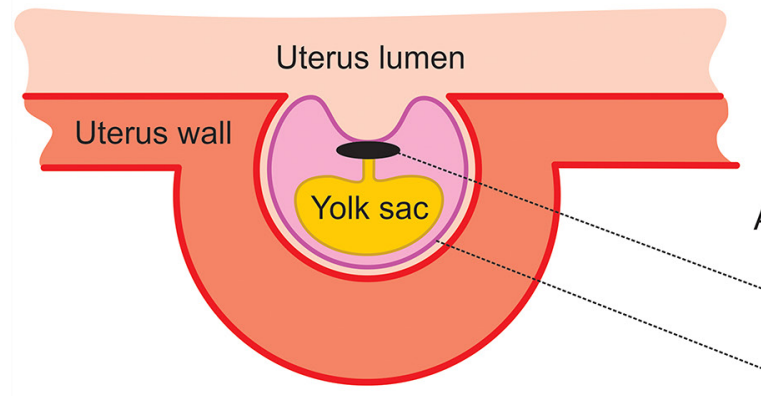

B) INTERSTITIAL

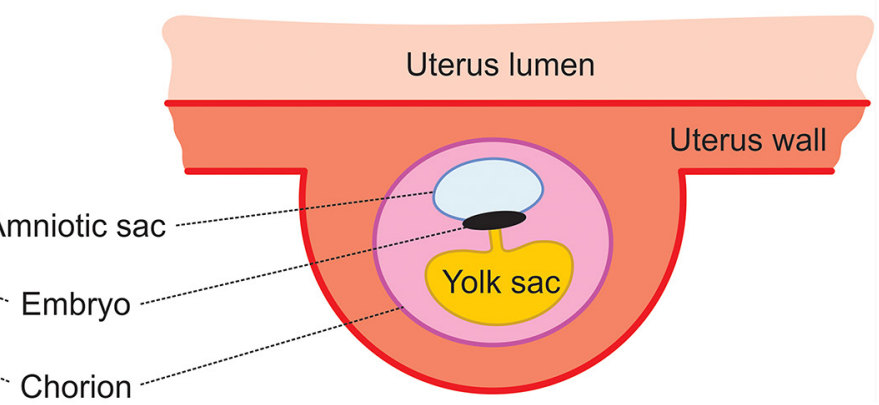

Figure 2. Differences between rodents (eccentric) and humans (interstitial) regarding the mode by which placentation takes place in early pregnancy. Note that in the eccentric type of placentation, the chorionic sac is within a "pocket" that is partially in contact with the uterine lumen, whereas in the interstitial type, the chorionic sac is entirely enveloped by the uterus wall keeping no contact with its lumen.

Table 5. Functional differences between the inverted yolk sac and the chorioallantoic placenta.

\begin{tabular}{lc}
\hline Placenta structure & Functional features \\
\hline Inverted yolk sac & $\begin{array}{c}\text { Mother Embryo exchanges by } \\
\text { (rodents: early pregnancy) }\end{array}$ \\
& $\begin{array}{c}\text { histiotrophic process; pinocytosis } \\
\text { (lysosome dependent process) by yolk } \\
\text { sac epithelial cells of macromolecules } \\
\text { found in maternal uterus secretions }\end{array}$
\end{tabular}

Chorioallantoic (primates, and definitive in rodents, after GD 11-11.5 in rats)
Exchanges between maternal and embryo/fetus circulation by a direct hemotrophic process

Exchanges of nutrients through hemotrophic process of chorioallantoic placenta are faster and more efficient than those mediated by histiotrophic process of inverted yolk placenta.

ca NPs reaching the fetal perfusate after $6 \mathrm{~h}$ was limited to 4.2 and $4.6 \%$ for 25 and $50 \mathrm{~nm} \mathrm{NPs}$, respectively, and that NPs are poorly transported across BeWo cells ${ }^{66}$.

The other side of the coin is that the selective delivery/ toxicity of NPs towards the placenta and embryo can eventually be useful for treating life-threatening medical conditions involving abnormal growth of the trophoblast such as ectopic pregnancy, choriocarcinoma and placenta accreta. In line with this, Kaitu'u-Lino et al. ${ }^{89}$ employed nanocells ${ }^{\mathrm{xv}}$ loaded with doxorubicin to deliver this chemotherapeutic drug to placental tissue. The authors showed that targeted NP+doxorubicin delivery induced marked regression of JEG-3 (choriocarcinoma cells) tumor xenografts in SCID mice. They also demonstrated that EGFR targeted NPs were readily taken up by human pla-

xv Kaitu'u-Lino et al ${ }^{89}$ used bacterially derived nanospheres (400nm in diameter) known as "EnGenelC Delivery Vehicles" (EDVs) to target the epidermal growth factor receptor (EGFR) and so promote trophoblast tissue specific delivery of the antineoplastic drug doxorubicin. Placental targeting was achieved with the presence of bispecific antibodies against EGFR on the sphere surface. Since EGFRs are highly expressed on the placenta surface, doxorubicin (an antiproliferative agent) was specifically delivered to the target abnormal tissue. It is of note that these EDV are larger than $100 \mathrm{~nm}$ in diameter, and so technically they do not fit the previous (arbitrary) definition of NP. 
cental explants ex vivo and then induced apoptosis and in an in vitro assay (JEG-3 cells) produced inhibition of cell viability and proliferation and enhanced apoptosis. Overall, laboratory results suggest that this is a feasible therapeutic approach for further clinical trials in female patients with abnormal trophoblast growth disorders.

\section{Conclusion}

Although required for assessing health risks to women, the evaluation of the reproductive and developmental toxicity of NPs has not kept pace with the extraordinary expansion of the number and diversity of new nanotechnology products introduced to everyday life in recent years.

As depicted in Tables 2 and 3, the experimental studies conducted as yet have provided indications that several types of NPs might have adverse effects on the embryonic development of invertebrates (sea urchin, oyster, freshwater snail), non-mammalian vertebrates (fish, frog) and mammals (rats, mice). Furthermore, a few rodent studies also found evidence that some developmentally toxic NPs pass through the placenta and reach the embryo/fetal compartment. However, differences in the development and function of the placenta in early pregnancy (e.g., inverted yolk sac in rats versus chorionic villi in humans) make the extrapolation of results from rodents to humans problematic. Apart from data from a small number of ex vivo studies (i.e., perfused placenta) we know next to nothing about the ability of human placenta to take up and transfer NPs to the embryo/fetus. As far as the authors are aware, there have been no studies where the developmental toxicity of NPs in non-human primates and mammals other than rodents has been investigated.

Several problems and largely unanswered questions have to be addressed before tracing a roadmap to a research strategy, or tiered test battery scheme, to uncover potential developmental health hazards posed by new nanotechnology products.

One of the biggest difficulties to be faced is that the nanomaterials already in use, and those undergoing development, encompass a broad diversity of NPs. As highlighted by Clark et al. ${ }^{90}$, even within a single class of engineered NPs, such as carbon-based or metal oxide NPs, there exist "a wide range of sizes and shapes, with different chemical compositions and surface modifications, all of which may affect behavior and toxicity". It therefore seems unfeasible to assess reproductive and developmental hazards by testing manufactured NPs on a case-by-case basis, particularly if in vivo mammalian tests are to be used. If a case-by-case approach is unrealistic, making generalizations about hazards posed by particular subsets of NPs is hindered by the limited experimental data so far available. Yet, our knowledge of the biological and toxic effects of this highly sophisticated and diverse group of materials is still too limited to make reliable generalizations based on classes, sizes, shapes or other features of NPs. In other words, if QSAR (Quantitative Structure Activity Relationship) computational models to identify reproductive and developmental hazards of single chemical molecules are still under construction ${ }^{91}$, building up similar in silico predictive models to identify structural alerts (involving combinations of sizes, shapes, chemical compositions and other features) for NPs is probably unachievable in the near future.

Another difficulty is the heterogeneity in the size and the instability of some NPs in physiological solutions. As previously mentioned, under certain experimental conditions some NPs tend to agglomerate with time and it has been shown that toxicity (pulmonary toxicity, cytotoxicity and embryotoxicity) of fresh (predominantly singlet) NPs may at times differ from that of aged (predominantly agglomerated) NPs ${ }^{49,92,93}$. Oxidation of and ion release from metal NPs may also influence their toxicity.

Finally, an important difficulty in producing a roadmap for a testing strategy is the limited predictive value of in vitro (embryonic stem cells test) and ex vivo (zebrafish) assays, which are high throughput screening tests for detecting the developmental toxicity of NPs. The aforementioned in vitro and ex vivo tests cannot detect adverse effects on mammalian embryo development that arise indirectly from a maternal toxic effect and/or placental dysfunctions caused by NPs. It is of note that in tiered testing schemes, which are designed to save time and resources, a first step (tier) negative result tends to be definitive because as a rule the substance is not subsequently tested in vivo. However, a positive finding in the first tier in vitro or ex vivo assay generally leads to confirmation in in vivo tests in rodents (second tier).

Differences between rodents and humans with respect to the structure and function of the placenta, particularly in early pregnancy, may eventually lead to false positive findings at this confirmatory testing step. Hence, more studies on the passage through and effects of NPs on human placental development and functioning are needed.

In this review the authors' focus was mainly on the evaluation of potential health hazards to development posed by engineered NPs, i.e., the first step (hazard identification) of risk assessment. Nonetheless it is worth mentioning that good quality data is also missing on quantitative estimations of human exposure (including women of childbearing age) to existent NPs and without this information it is impossible properly to assess and manage their health risks.

The identification of potential hazards and the assessment of human health risks posed by the myriad of novel nanotechnology products is one of the challenges currently faced by toxicologists, particularly by those who deal with reproductive and developmental toxicology. Actually, any safe use of this fascinating novel technology in medicine and consumer products requires an equally innovative toxicological testing approach.

\section{Acknowledgments}

The authors are grateful to Heloisa Maria Nogueira Diniz and Genilton José Vieira for preparing the figures. 


\section{References}

1. Toumey C. Reading Feynman into nanotechnology: A text for a new science. Techné. 2008;12(3):133-68.

2. Service RF. Nanotoxicology. Nanotechnology growths up. Science. 2004;304(5678):1732-4.

3. Drexler KE. Nanotechnology: the past and the future. Science. 1992;255(5042):268-9.

4. Whatmore RW. Nanotechnology: What is it ? Should we be worried ? Occup Med (London). 2006;56(5): 295-9.

5. McCray WP. "Will Small Be Beautiful? Making Policies for Our Nanotech Future". History and Technology. 2005;21(2):177-203.

6. Plentz F, Fazzio A. Considerações sobre o Programa Brasileiro de Nanotecnologia. Ciência e Cultura. 2013;65(3):23-7.

7. Ministério da Ciência, Tecnologia e Inovação (BR). Desenvolvimento da Nanociência e da Nanotecnologia [Internet]. Brasília: MCTI; 2003. [acesso em 08 set. 2013]. Disponível em: http://www.mct.gov.br/upd_blob/0002/2361.pdf

8. Maynard AD. Don't define nanomaterials. Nature. 2011;475(7354):31.

9. Code of Federal Regulation (US). Title 29 - Labor: Subtitle B - Regulations Relating to Labor: Chapter XVII - Occupational safety and health administration, Department of labor: Part 1910 - Occupational safety and health standards: Subpart Z - Toxic and Hazardous Substances [internet]. Washington: CRF; 2006. [acesso em 01 nov. 2013]. Disponível em; http://www.gpo.gov/fdsys/pkg/CFR-2006-title29-vol6/pdf/CFR-2006-title29-vol6-part1910.pdf.

10. Morigi V, Tocchio A, Bellavite Pellegrini C, Sakamoto JH, Arnone $M$, Tasciotti E. Nanotechnology in medicine: from inception to market domination. J Drug Deliv. 2012;2012:389485.

11. Thorley AJ, Tetley TD. New perspectives in nanomedicine. Pharmacol Ther. 2013;140(2):176-85.

12. Varshney HM, Shailender M. Nanotechnology" Current Status in Pharmaceutical Science: a review. Int J Ther Appl. 2012;6:14-24.

13. Date AA, Patil RR, Panicucci R, Souto EB, Lee RW. Translating nanotechnology from bench to pharmaceutical market: barriers, success, and promises. J Drug Deliv. 2012; 2012:678910.

14. Kesisoglou F, Panmai S, Wu Y. Nanosizing--oral formulation development and biopharmaceutical evaluation. Adv Drug Deliv Rev. 2007;59(7):631-44.

15. Takagi T, Ramachandran C, Bermejo M, Yamashita S, Yu LX, Amidon GL. A provisional biopharmaceutical classification of the top 200 oral drug products in the United States, Great Britain, Spain, and Japan. Mol Pharm. 2006;3(6):631-43.

16. Vyas TK, Shahiwala A, Amiji MM. Improved oral bioavailability and brain transport of Saquinavir upon administration in novel nanoemulsion formulations. Int J Pharm. 2008;347(1-2):93-101.

17. Rios-Doria J, Carie A, Costich T, Burke B, Skaff H, Panicucci $\mathrm{R}$, Sill K. A versatile polymer micelle drug delivery system for encapsulation and in vivo stabilization of hydrophobic anticancer drugs. J Drug Deliv. 2012;2012:951741.
18. Matsumura $\mathrm{Y}$, Maeda H. A new concept for macromolecular therapeutics in cancer chemotherapy: mechanism of tumoritropic accumulation of proteins and the antitumor agent smancs. Cancer Res. 1996; 46(12 Pt 1):6387-92.

19. Sengupta P, Basu S, Soni S, Pandey A, Roy B, Oh MS, Chin KT, Paraskar AS, Sarangi S, Connor Y, Sabbisetti VS, Kopparam J, Kulkarni A, Muto K, Amarasiriwardena C, Jayawardene I, Lupoli N, Dinulescu DM, Bonventre JV, Mashelkar RA, Sengupta S. Cholesterol-tethered platinum II-based supramolecular nanoparticle increases antitumor efficacy and reduces nephrotoxicity. Proc Natl Acad Sci U S A. 2012;109(28):11294-9.

20. Yuan F, Dellian M, Fukumura D, Leunig M, Berk DA, Torchilin VP, Jain RK. Vascular permeability in a human tumor xenograft: molecular size dependence and cutoff size. Cancer Res. 1995; 55(17):3752-6.

21. Hashizume H, Baluk P, Morikawa S, McLean JW, Thurston $G$, Roberge S, Jain RK, McDonald DM. Openings between defective endothelial cells explain tumor vessel leakiness. Am J Pathol. 2000;156(4):1363-80.

22. Baluk P, Hashizume H, McDonald DM. Cellular abnormalities of blood vessels as targets in cancer. Curr Opin Genet Dev. 2005;15(1):102-11.

23. Powell AC, Paciotti GF, Libutti SK. Colloidal gold: a novel nanoparticle for targeted cancer therapeutics. Methods Mol Biol. 2010;624:375-84.

24. Libutti SK, Paciotti GF, Byrnes AA, Alexander HR Jr, Gannon WE, Walker M, Seidel GD, Yuldasheva N, Tamarkin L. Phase I and pharmacokinetic studies of CYT-6091, a novel PEGylated colloidal gold-rhTNF nanomedicine. Clin Cancer Res. 2010;16(24):6139-49.

25. Donaldson K, Stone V, Tran CL, Kreyling W, Borm PJ. Nanotoxicology. Occup Environ Med. 2004;61(9):727-8.

26. Seaton A, Donaldson K. Nanoscience, nanotoxicology, and the need to think small. Lancet. 2005;365(9463):923-4.

27. Oberdörster G, Oberdörster E, Oberdörster J. Nanotoxicology: an emerging discipline evolving from studies of ultrafine particles. Environ Health Perspect. 2005;113(7):823-39.

28. Kurath M, Maasen S. Toxicology as a nanoscience? Disciplinary identities reconsidered. Part Fibre Toxicol. 2006;3:6.

29. Maynard AD, Warheit DB, Philbert MA. The new toxicology of sophisticated materials: nanotoxicology and beyond. Toxicol Sci. 2011;120 Suppl 1:S109-29.

30. Oberdörster G, Finkelstein JN, Johnston C, Gelein R, Cox C, Baggs R, Elder AC. Acute pulmonary effects of ultrafine particles in rats and mice. Res Rep Health Eff Inst. 2000;(96):5-74; disc. 75-86.

31. Oberdörster G. Pulmonary effects of inhaled ultrafine particles. Int Arch Occup Environ Health. 2001;74(1):1-8.

32. Oberdörster G, Sharp Z, Atudorei V, Elder A, Gelein R, Lunts A, Kreyling W, Cox C. Extrapulmonary translocation of ultrafine carbon particles following whole-body inhalation exposure of rats. J Toxicol Environ Health A. 2002;65(20):1531-43. 
33. Oberdörster G, Sharp Z, Atudorei V, Elder A, Gelein R, Kreyling W, Cox C. Translocation of inhaled ultrafine particles to the brain. Inhal Toxicol. 2004;16(6-7):437-45.

34. Oberdörster G, Ferin J, Gelein R, Soderholm SC, Finkelstein J. Role of the alveolar macrophage in lung injury: studies with ultrafine particles. Environ Health Perspect. 1992;97:193-9.

35. Ferin J. Pulmonary retention and clearance of particles. Toxicol Lett. 1994;72(1-3):121-5.

36. Silbergeld EK, Contreras EQ, Hartung T, Hirsch C, Hogberg $H$, Jachak AC, Jordan W, Landsiedel R, Morris J, Patri A, Pounds JG, de Vizcaya Ruiz A, Shvedova A, Tanguay R, Tatarazako N, van Vliet E, Walker NJ, Wiesner M, Wilcox N, Zurlo J. $\mathrm{t} \square$ workshop report. Nanotoxicology: "the end of the beginning" - signs on the roadmap to a strategy for assuring the safe application and use of nanomaterials. ALTEX. 2011;28(3):236-41.

37. Kante B, Couvreur P, Dubois-Krack G, De Meester C, Guiot P, Roland M, Mercier M, Speiser P. Toxicity of polyalkylcyanoacrylate nanoparticles I: Free nanoparticles. J Pharm Sci. 1982;71(7):786-90.

38. Ema M, Kobayashi N, Naya M, Hanai S, Nakanishi J. Reproductive and developmental toxicity studies of manufactured nanomaterials. Reprod Toxicol. 2010;30(3):343-52.

39. Campagnolo L, Massimiani M, Magrini A, Camaioni A, Pietroiusti A. Physico-chemical properties mediating reproductive and developmental toxicity of engineered nanomaterials. Curr Med Chem. 2012;19(26):4488-94.

40. Sun J, Zhang Q, Wang Z, Yan B. Effects of nanotoxicity on female reproductivity and fetal development in animal models. Int J Mol Sci. 2013;14(5):9319-37.

41. Juch H, Nikitina L, Debbage P, Dohr G, Gauster M. Nanomaterial interference with early human placenta: Sophisticated matter meets sophisticated tissues. Reprod Toxicol. 2013;41:73-9.

42. Lee KJ, Nallathamby PD, Browning LM, Osgood CJ, Xu XH. In vivo imaging of transport and biocompatibility of single silver nanoparticles in early development of zebrafish embryos. ACS Nano. 2007;1 (2):133-43.

43. Zhao X, Wang S, Wu Y, You H, Lv L. Acute ZnO nanoparticles exposure induces developmental toxicity, oxidative stress and DNA damage in embryo-larval zebrafish. Aquat Toxicol. 2013;136-137:49-59.

44. Siller L, Lemloh ML, Piticharoenphun S, Mendis BG, Horrocks BR, Brümmer F, Medaković D. Silver nanoparticle toxicity in sea urchin Paracentrotus lividus. Environ Pollut. 2013;178:498-502.

45. Kim KT, Zaikova T, Hutchison JE, Tanguay RL. Gold nanoparticles disrupt zebrafish eye development and pigmentation. Toxicol Sci. 2013;133(2):275-88.

46. Kim JY, Kim KT, Lee BG, Lim BJ, Kim SD. Developmental toxicity of Japanese medaka embryos by silver nanoparticles and released ions in the presence of humic acid. Ecotoxicol Environ Saf. 2013;92:57-63.
47. Gambardella C, Aluigi MG, Ferrando S, Gallus L, Ramoino P, Gatti AM, Rottigni M, Falugi C. Developmental abnormalities and changes in cholinesterase activity in sea urchin embryos and larvae from sperm exposed to engineered nanoparticles. Aquat Toxicol. 2013;130-131:77-85.

48. Musee N, Oberholster PJ, Sikhwivhilu L, Botha AM. The effects of engineered nanoparticles on survival, reproduction, and behaviour of freshwater snail, Physa acuta (Draparnaud, 1805). Chemosphere. 2010;81(10):1196-203.

49. Truong L, Zaikova T, Richman EK, Hutchison JE, Tanguay RL. Media ionic strength impacts embryonic responses to engineered nanoparticle exposure. Nanotoxicology. 2012;6(7):691-9.

50. Ringwood AH, Levi-Polyachenko N, Carroll DL. Fullerene exposures with oysters: embryonic, adult, and cellular responses. Environ Sci Technol. 2009;43(18):7136-41.

51. Fent K, Weisbrod CJ, Wirth-Heller A, Pieles U. Assessment of uptake and toxicity of fluorescent silica nanoparticles in zebrafish (Danio rerio) early life stages. Aquat Toxicol. 2010;100 (2):218-28.

52. Bacchetta R, Santo N, Fascio U, Moschini E, Freddi S, Chirico G, Camatini M, Mantecca P. Nano-sized $\mathrm{CuO}, \mathrm{TiO}_{2}$ and $\mathrm{ZnO}$ affect Xenopus laevis development. Nanotoxicology. 2012;6(4):381-98.

53. Bar-Ilan O, Louis KM, Yang SP, Pedersen JA, Hamers RJ, Peterson RE, Heideman W. Titanium dioxide nanoparticles produce phototoxicity in the developing zebrafish. Nanotoxicology. 2012;6(6):670-9.

54. Cheng J, Flahaut E, Cheng SH. Effect of carbon nanotubes on developing zebrafish (Danio rerio) embryos. Environ Toxicol Chem. 2007;26(4): 708-16.

55. Lee KJ, Nallathamby PD, Browning LM, Osgood CJ, Xu XH. In vivo imaging of transport and biocompatibility of single silver nanoparticles in early development of zebrafish embryos. ACS Nano. 2007;1(2):133-43.

56. Kimmel CB, Ballard WW, Kimmel SR, Ullmann B, Schilling TF. Stages of embryonic development of the zebrafish. Dev Dyn. 1995;203(3):253-310.

57. Henn K, Braunbeck T. Dechorionation as a tool to improve the fish embryo toxicity test (FET) with the zebrafish (Danio rerio). Comp Biochem Physiol C Toxicol Pharmacol. 2011;153(1):91-8.

58. Mandrell D, Truong L, Jephson C, Sarker MR, Moore A, Lang C, Simonich MT, Tanguay RL. Automated zebrafish chorion removal and single embryo placement: optimizing throughput of zebrafish developmental toxicity screens. J Lab Autom. 2012;17(1):66-74.

59. Usenko CY, Harper SL, Tanguay RL. Fullerene C60 exposure elicits an oxidative stress response in embryonic zebrafish. Toxicol Appl Pharmacol. 2008;229(1):44-55.

60. Campagnolo L, Fenoglio I, Massimiani M, Magrini A, Pietroiusti A. Screening of nanoparticle embryotoxicity using embryonic stem cells. Methods Mol Biol. 2013;1058:49-60.

61. Pietroiusti A, Massimiani M, Fenoglio I, Colonna M, Valentini F, Palleschi G, Camaioni A, Magrini A, Siracusa G, Berga- 
maschi A, Sgambato A, Campagnolo L. Low doses of pristine and oxidized single-wall carbon nanotubes affect mammalian embryonic development. ACS Nano. 2011;5(6):4624-33.

62. Park MV, Annema W, Salvati A, Lesniak A, Elsaesser A, Barnes C, McKerr G, Howard CV, Lynch I, Dawson KA, Piersma AH, de Jong $\mathrm{WH}$. In vitro developmental toxicity test detects inhibition of stem cell differentiation by silica nanoparticles. Toxicol Appl Pharmacol. 2009;240(1):108-16.

63. Myllynen P, Pasanen M, Pelkonen O. Human placenta: a human organ for developmental toxicology research and biomonitoring. Placenta. 2005;26(5):361-71.

64. Menezes V, Malek A, Keelan JA. Nanoparticulate drug delivery in pregnancy: placental passage and fetal exposure. Curr Pharm Biotechnol. 2011;12(5):731-42.

65. Saunders M. Transplacental transport of nanomaterials. Wiley Interdiscip Ver Nanomed Nanobiotechnol. 2009;1(6):671-84.

66. Sønnegaard Poulsen M, Mose T, Leth Maroun L, Mathiesen L, Ehlert Knudsen L, Rytting E. Kinetics of silica nanoparticles in the human placenta. Nanotoxicology. 2013. [Ahead of print]. doi: 10.3109/17435390.2013.812259

67. Myllynen PK, Loughran MJ, Howard CV, Sormunen R, Walsh AA, Vähäkangas KH. Kinetics of gold nanoparticles in the human placenta. Reprod Toxicol. 2008;26(2):130-7.

68. Wick P, Malek A, Manser P, Meili D, Maeder-Althaus X, Diener L, Diener PA, Zisch A, Krug HF, von Mandach U. Barrier capacity of human placenta for nanosized materials. Environ Health Perspect. 2010;118(3):432-6.

69. Leconte I, Mouche I. Frog embryo teratogenesis assay on Xenopus and predictivity compared with in vivo mammalian studies. Methods Mol Biol. 2013;947:403-21.

70. Hougaard KS, Jackson P, Kyjovska ZO, Birkedal RK, De Temmerman PJ, Brunelli A, Verleysen E, Madsen AM, Saber AT, Pojana G, Mast J, Marcomini A, Jensen KA, Wallin H, Szarek J, Mortensen A, Vogel U. Effects of lung exposure to carbon nanotubes on female fertility and pregnancy. A study in mice. Reprod Toxicol. 2013;41:86-97.

71. Yoshida S, Hiyoshi K, Oshio S, Takano H, Takeda K, Ichinose $T$. Effects of fetal exposure to carbon nanoparticles on reproductive function in male offspring. Fertil Steril. 2010;93(5):1695-9.

72. Hougaard KS, Jackson P, Jensen KA, Sloth JJ, Löschner K, Larsen EH, Birkedal RK, Vibenholt A, Boisen AM, Wallin H, Vogel U. Effects of prenatal exposure to surface-coated nanosized titanium dioxide (UV-Titan). A study in mice. Part Fibre Toxicol. 2010;7:16.

73. Tian X, Zhu M, Du L, Wang J, Fan Z, Liu J, Zhao Y, Nie G. Intrauterine inflammation increases materno-fetal transfer of gold nanoparticles in a size-dependent manner in murine pregnancy. Small. 2013;9(14):2432-9.

74. Lim JH, Kim SH, Shin IS, Park NH, Moon C, Kang SS, Kim SH, Park SC, Kim JC. Maternal exposure to multi-wall carbon nanotubes does not induce embryo-fetal developmental toxicity in rats. Birth Defects Res B Dev Reprod Toxicol. 2011;92(1):69-76.
75. Shimizu M, Tainaka H, Oba T, Mizuo K, Umezawa M, Takeda K. Maternal exposure to nanoparticulate titanium dioxide during the prenatal period alters gene expression related to brain development in the mouse. Part Fibre Toxicol. 2009;6:20.

76. Jackson P, Hougaard KS, Vogel U, Wu D, Casavant L, Williams A, Wade M, Yauk CL, Wallin H, Halappanavar S. Exposure of pregnant mice to carbon black by intratracheal instillation: toxicogenomic effects in dams and offspring. Mutat Res. 2012;745(1-2):73-83.

77. Jo E, Seo G, Kwon JT, Lee M, Lee Bc, Eom I, Kim P, Choi K. Exposure to zinc oxide nanoparticles affects reproductive development and biodistribution in offspring rats. J Toxicol Sci. 2013;38(4):525-30.

78. Umezawa M, Tainaka H, Kawashima N, Shimizu M, Takeda $K$. Effect of fetal exposure to titanium dioxide nanoparticle on brain development - brain region information. J Toxicol Sci. 2012;37(6):1247-52.

79. Zalgevičienè V, Kulvietis V, Bulotienè $D$, Didžiapetrienè $\mathrm{J}$, Rotomskis R. The effect of nanoparticles in rats during critical periods of pregnancy. Medicina (Kaunas). 2012; 48(5):256-64

80. Fujitani T, Ohyama K, Hirose A, Nishimura T, Nakae D, Ogata A. Teratogenicity of multi-wall carbon nanotube (MWCNT) in ICR mice. J Toxicol Sci. 2012;37(1):81-9.

81. Blum JL, Xiong JQ, Hoffman C, Zelikoff JT. Cadmium associated with inhaled cadmium oxide nanoparticles impacts fetal and neonatal development and growth. Toxicol Sci. 2012;126(2):478-86.

82. Chu M, Wu Q, Yang H, Yuan R, Hou S, Yang Y, Zou Y, Xu S, $\mathrm{Xu} \mathrm{K}$, Ji A, Sheng L. Transfer of quantum dots from pregnant mice to pups across the placental barrier. Small. 2010;6(5):670-8.

83. Chan WH, Shiao NH. Cytotoxic effect of CdSe quantum dots on mouse embryonic development. Acta Pharmacol Sin.2008; 29(2):259-66.

84. Campagnolo L, Massimiani M, Palmieri G, Bernardini R, Sacchetti C, Bergamaschi A, Vecchione L, Magrini A, Bottini $M$, Pietroiusti A. Biodistribution and toxicity of pegylated single wall carbon nanotubes in pregnant mice. Part Fibre Toxicol. 2013;10(1):21.

85. Carney EW, Scialli AR, Watson RE, DeSesso JM. Mechanisms regulating toxicant disposition to the embryo during early pregnancy: an interspecies comparison. Birth Defects Res C Embryo Today. 2004; 72(4):345-60.

86. Freyer C, Renfree MB. The mammalian yolk sac placenta. J Exp Zool B Mol Dev Evol. 2009; 312(6):545-54.

87. Williams KE, Roberts G, Kidston ME, Beck F, Lloyd JB. Inhibition of pinocytosis in rat yolk sac by trypan blue. Teratology. 1976;14(3):343-54.

88. Gulamhusein AP, Moore WJ, Gupta M, Beck F. Trypan blue teratogenesis in the rat: further observations in vitro. Teratology. 1982; 26(3):289-97.

89. Kaitu'u-Lino TJ, Pattison S, Ye L, Tuohey L, Sluka P, MacDiarmid J, Brahmbhatt H, Johns T, Horne AW, Brown J, Tong S. Targeted nanoparticle delivery of doxorubicin into 
placental tissues to treat ectopic pregnancies. Endocrinology. 2013;154(2):911-9.

90. Clark KA, White RH, Silbergeld EK. Predictive models for nanotoxicology: current challenges and future opportunities. Regul Toxicol Pharmacol. 2011;59(3):361-3.

91. Matthews EJ, Kruhlak NL, Daniel Benz R, Contrera JF. A comprehensive model for reproductive and developmental toxicity hazard identification: I. Development of a weight of evidence QSAR database. Regul Toxicol Pharmacol. 2007;47(2):115-35.

Data de recebimento: 15/09/2013

Data de aceite: $27 / 11 / 2013$
92. Gualtieri M, Skuland T, Iversen TG, Låg M, Schwarze P, Bilaničová D, Pojana G, Refsnes $M$. Importance of agglomeration state and exposure conditions for uptake and pro-inflammatory responses to amorphous silica nanoparticles in bronchial epithelial cells. Nanotoxicology. 2012;6(7):700-12.

93. Zook JM, Maccuspie RI, Locascio LE, Halter MD, Elliott JT. Stable nanoparticle aggregates/agglomerates of different sizes and the effect of their size on hemolytic cytotoxicity. Nanotoxicology. 2011;5(4):517-30. 